\title{
Modification of Coronary-Prone Behaviors in Coronary Patients of Low Socio-Economic Status
}

\author{
Antonio del Pino ${ }^{1}, \mathrm{M}^{\mathrm{a}}$ Teresa Gaos ${ }^{1}$, Ruth Dorta ${ }^{1}$, and Martín García ${ }^{2}$ \\ ${ }^{1}$ La Laguna University \\ ${ }^{2}$ Cardiology Service of La Laguna University Hospital
}

\begin{abstract}
The purpose of this study is to determine the effectiveness of a group cognitive-behavioral treatment to modify coronary-prone behaviors in patients from a fairly low social and educational level. Participants were 98 male coronary patients randomly allocated to one experimental and two control groups. All groups received standard medical treatment. The experimental group received an additional psychological treatment and one of the two control groups received a health education treatment. Results showed that only the psychological treatment group significantly reduced Pressured Drive and Speed-Impatience after treatment, and at 1- and 2-year follow-ups. Depression was also significantly reduced only in this group at 2-year follow-up. The results are considered a reliable first step in the process of validating this program designed to improve coronary heart disease patients' quality of life.

Keywords: coronary patients, coronary-prone behaviors, depression, low socio-economic status, cognitive-behavioral treatment, Type A behavior
\end{abstract}

\begin{abstract}
Este estudio pretende conocer la efectividad de un tratamiento cognitivo-conductual aplicado a grupos de enfermos coronarios de un nivel educativo y status social predominantemente bajo para modificar conductas prono-coronarias. Método: La distribución de los 98 varones enfermos coronarios en un grupo experimental y dos de control se realizó al azar. Los tres grupos recibieron el tratamiento médico estándar. El grupo experimental recibió adicionalmente un tratamiento psicológico y uno de los dos grupos de control recibió además un programa de educación para la salud. Los resultados mostraron que sólo el grupo que recibió el tratamiento psicológico redujo significativamente su Comportamiento Apresurado y su Prisa-Impaciencia después del tratamiento y durante los dos años de seguimiento posteriores al tratamiento. La depresión también se redujo sólo en este grupo tras los dos años de seguimiento. Los resultados se consideran un primer paso fiable en el proceso de validar este programa diseñado para mejorar la calidad de vida de los pacientes coronarios.

Palabras clave: pacientes coronarios, conductas prono-coronarias, depresión, estatus socio-económico bajo, tratamiento cognitivo-conductual, conducta tipo $A$
\end{abstract}

This study was financed by the Autonomous Government of the Canary Islands. We gratefully acknowledge Margaret Gillon Dowens and Dulce $\mathrm{M}^{\mathrm{a}}$ Rodríguez for their revision of the English text and the anonymous reviewers for their suggestions. We are also indebted to M. Friedman and the co-workers of the San Francisco Coronary/Cancer Prevention Project and acknowledge their influence, particularly concerning procedure.

Correspondence concerning this article should be addressed to: Antonio del Pino, Department of Personality, Assessment, and Psychological Treatments. La Laguna University. Campus de Guajara, 38205. La Laguna. Islas Canarias (Spain). E-mail: apino@ull.es 
The results of the psychological interventions carried out until fifteen years ago for the type A behavior pattern and for coronary heart disease were reflected in the meta-analysis of Nunes, Frank, and Kornfeld (1987). The effect sizes of the Type-A behavior pattern (TABP) change ranged from 0.02 to 1.27 , with a mean of 0.61 . No single treatment modality could be considered efficacious, although the change of the TABP effect size did correlate positively and significantly with the number of treatment modalities used, and the combination of an educational component, a coping method, either relaxation or cognitive therapy, and a behavioral rehearsal achieved the most significant TABP changes. Fernández-Abascal, Martín, and Domínguez (2003) reviewed this issue in detail.

Linden, Stossel, and Maurice (1996) found in their metaanalysis that the addition of psychosocial treatment to standard cardiac rehabilitation regimes reduced psychological distress during the first 2 years and that the patients who did not receive psychosocial treatment had greater mortality and cardiac recurrence rates during the first 2 years of followup. The meta-analysis of Dusseldorp, van Elderen, Maes, Meulman, and Kraaij (1999) examined the effects of psychoeducational programs for coronary heart disease (CHD) patients. The results suggest positive distal effects (34\% reduction in cardiac mortality, and $29 \%$ reduction in recurrence of myocardial infarction) and significant positive effects on proximal targets such as blood pressure, cholesterol, and smoking behavior, but not on anxiety or depression.

The authors of these meta-analyses point out that these programs should be adapted to the characteristics of different groups of patients, especially groups of low socio-economic status (Smith, Kendall, \& Keefe, 2002), and the priority of discovering the active components of the programs, so as to reduce their duration and improve cost-benefit relationships.

The present study is an attempt to validate a treatment program. While we acknowledge the influence, particularly concerning procedure, of M. Friedman and co-workers from the San Francisco Coronary/Cancer Prevention Project, however, our theoretical perspective is closer to the cognitive-behavioral orientation of Roskies (1987).

The aim of this study is to determine the effectiveness of a cognitive-behavioral intervention trial to modify coronary-prone behaviors, specifically the TABP components, in people from a fairly low social and educational level who have suffered from angina pectoris and/or myocardial infarction. Using the treatment package strategy (Kazdin, \& Wilson, 1978), we began by elaborating a wide spectrum cognitive-behavioral treatment package, so that in subsequent research this treatment package could be dismantled.

\section{Method}

\section{Sample and Selection Procedure}

The sample was composed of males treated in the University Hospital of the Canary Islands. The climate of this region is mild and the life-style largely rural, the most important economic activities involving service to the tourism industry. The pace of life in the islands is, therefore, rather slower than in more industrialized areas.

All the patients treated in the Cardiologist Service between the years 1992-1995 were given information about secondary prevention of CHD by a cardiologist and were invited to participate in the project if they fulfilled the following three conditions: (a) reliably documented evidence of CHD (in most cases after catheterization), (b) no recommendation of immediate surgical intervention, and (c) no medical or psychological co-morbidity requiring individual intervention.

The project was developed in three stages or years. At the beginning of each year, a meeting was organized with the first 60 coronary patients who fulfilled the eligibility requirements and had expressed interest in the project while in hospital. At this meeting, the patients were given a short explanation of the advantages of participating in a Psychological Treatment (PsT) program or a Health Education Treatment (HET) program to prevent reoccurrence of coronary episodes. The need for participants in the control group, who received only the University Hospital standard medical treatment (SMT) program for coronary patients was also explained, as was the calendar of the treatment programs and the responsibilities acquired by the participants.

After this meeting, the research team allocated the participants to the various groups. The first 40 volunteers were allocated at random either to the PsT or the HET groups, and the last 20 to volunteer, or those who would have had difficulty in attending the treatment sessions at that time, were assigned to the SMT control group. The research design thus involved one experimental group, which received the SMT and the PsT, and two control groups, one that received both the SMT and the HET, and the other that received only the SMT. This latter group was, in fact, a waiting-list control group, as the members had the opportunity to participate in the psychological or educational treatment groups in subsequent years of the project.

At a second meeting, the patients who were still interested in the program filled out a form with their personal data and signed their free consent to participate and to acknowledge their awareness of the commitment they assumed as participants. In this session, the nurses and the psychologists in charge of the treatments and a physician acting for the University Hospital also signed the responsibilities that each assumed. The participants also filled in the psychological tests and questionnaires. After this session, the psychologist in charge of the program had an individual meeting with each participant to inform them to which group they had been assigned.

In the first year of the project, both the PsT and HET groups were randomly drawn and allocated, but the resulting differences in education within the generally low educational level of the groups made it difficult to carry out the treatment programs and to achieve intragroup interaction. 
Therefore, in the following years, we decided to employ stratified allocation. Two groups were formed according to educational level, they were assigned a treatment program at random, and this was alternated the following year.

Each year, there was the same number of patients in the SMT control group as in the PsT and HET groups. The total size of the sample was exclusively determined by the number of volunteers, as information about the program was given to all the patients of the Cardiology Service during the 3-year duration of the project.

\section{Instruments}

The dependent variables were assessed in group by the first author of this paper, assisted by a minimum of three collaborating psychologists. The Structured Interview was necessarily carried out individually.

The Framingham Type-A Scale (FTAS; Haynes, Levine, Scotch, Feinleib, \& Kannel, 1978). This scale measures Pressured Drive and Competitiveness/Impatience (Houston, Smith, \& Zuraswski, 1986; del Pino, Gaos, \& Dorta, 1997). We used the version translated and adapted by del Pino, Borges, Díaz, Suárez, and Rodríguez (1990).

The Structured Interview (SI; Chesney, Eagleston, \& Rosenman, 1980). The SI was applied as indicated in del Pino, Gaos, and Dorta (1999). The SI is made up of three factors (Competitiveness/Hard Driving, Anger-Out, and Speed/Impatience). All the interviews were carried out by two trained collaborators and the recordings of the interviews were evaluated by a person who was ignorant of the research project and specially trained for this evaluation task.

The Multidimensional Anger Inventory (MAI; Siegel, 1986). A version translated and adapted by Sánchez-Elvira, Pérez, and Bermúdez (1991) was employed. This questionnaire evaluates four factors (Anger/Arousal, Hostile Outlook, Anger-In, and Anger-Out) and a Total Anger Scale calculated by adding the individual's scores over the four factors.

The Beck Depression Inventory (BDI; Beck, Ward, Mendelson, Mock, \& Erbaugh, 1961). We used the Spanish adapted translation by Conde, Esteban, and Useros (1976).

\section{Procedure}

The total number of sessions and general training procedure were the same in the PsT and the HET groups.

The PsT, summarized in del Pino (1998), consisted of five parts:

1. Introduction to CHD and its contributing factors.

2. Tension control, including: (a) physical tension, particularly relaxation practice; (b) behavioral tension (time urgency); (c) modification of dysfunctional thoughts, substituting them with productive thinking; and (d) modification of negative emotions (angerhostility and frustration).
3. Stress management, working on recognition of personal triggers and on how to cope with stressful situations.

4. Planning and learning to enjoy events to reduce tension and stress.

5. Lifestyle change as a lifetime aim.

The content and homework for each session and suggestions for the participants were provided in the Participant's Guide, which was given to all the participants in the PsT. All training sessions were directed and taught by the first author of this article, with the collaboration of the same three psychologists during the 3-year project. To ensure the integrity and quality of the treatment, a Therapist's Guide was compiled.

The HET consisted of the following modules:

1. Heart anatomy and physiology.

2. CHD: a) clinical manifestations and treatment modalities, b) signs and alarm symptoms, c) risk factors.

3. Recommended lifestyle, including advice about changing diet and certain patterns of coronary-prone behaviors.

4. Medication: dosage conditions and effects.

The HET program was taught by a team of three nurses who are teachers from the University of La Laguna School of Nursing.

The 90-minute sessions involved an oral presentation backed up by audiovisual material, followed by a questionand-answer period. At the end of each session, the group leaders gave out homework that was checked at the beginning of the following session with the patients' active participation.

Both HET and the PsT were carried out in 24 group sessions over a 9-month period, 12 meetings during the first 3 months, and 12 meetings during the following 6 months. In the 10 months following the treatment programs, there were 10 sessions (once a month) to maintain the effects of the treatments.

Each group was comprised of a number of people that ranged between a maximum of 12 and a minimum of 8 .

\section{Data Analysis}

The effects of the treatment were analyzed by a repeated measures general linear model. The results at 1 year were analyzed by a $3 \times 2$ factorial design, with one betweengroup factor with three levels (PsT, HET, and SMT) and one within-group factor (the time of measure, with two times: before and after treatment). The treatment effects, including the 2 years of follow-up, were analyzed using a $2 \times 4$ design with one between-group factor with two levels (PsT and HET) and one within-group factor with four levels (times of measure: before treatment, after concluding treatment, and at 1- and 2-year follow-up). All analyses were carried out using the SPSS 10.0 computer program. 


\section{Results}

The recruitment process and the results of this can be seen in Diagram I.

Average attendance across the 24 sessions of the program in the PsT group was 20.64 (86\% of the sessions) and $19.68(82 \%)$ in the HET group, with a range of attendance in each group of 12-24 individuals. Dropouts in the treatment groups were those who did not attend $50 \%$ of meetings. In the control group, we included as dropouts those who only filled in all the questionnaires once.

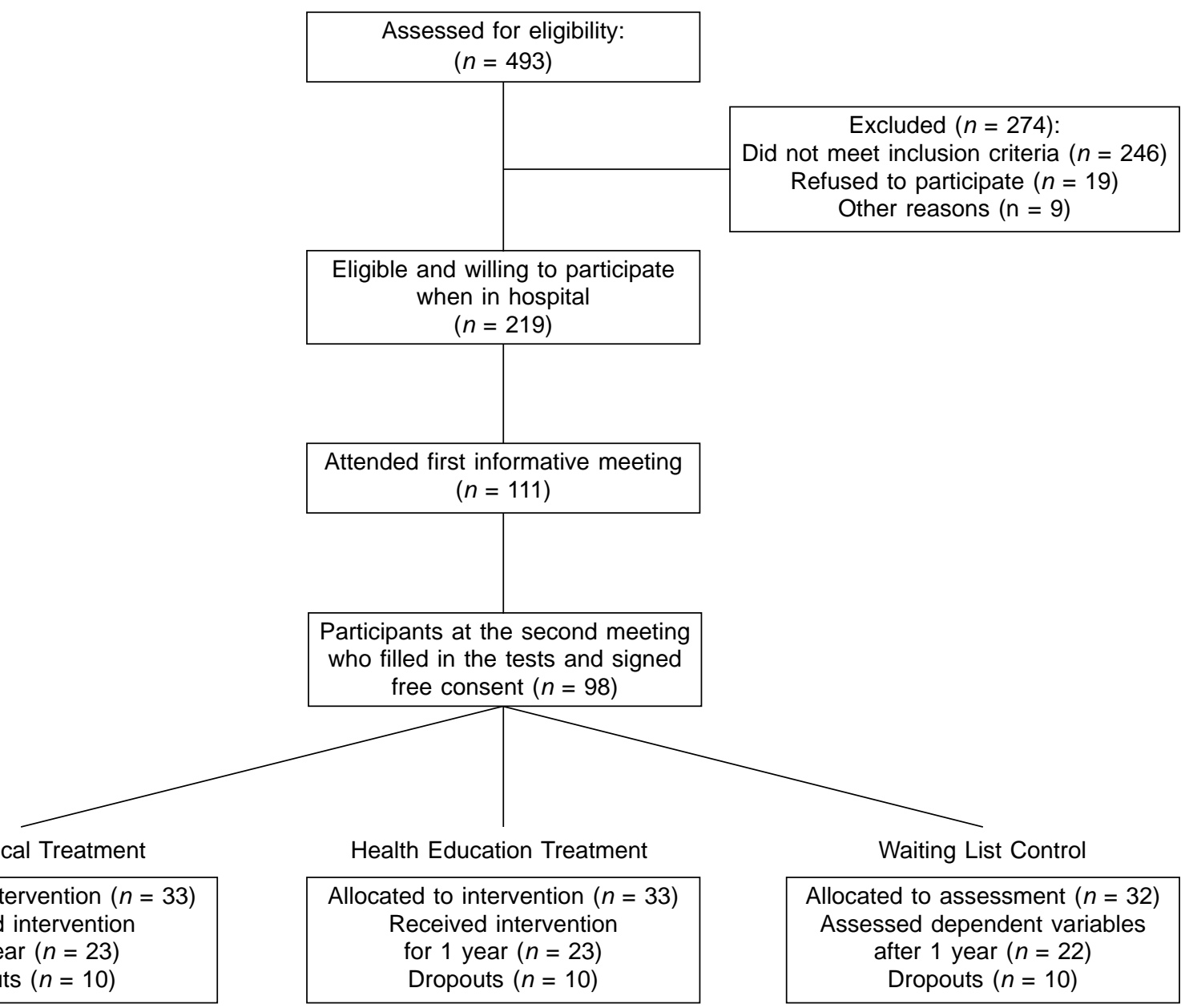

1-year follow-up: $n=19$

2-year follow-up: $n=19$

Lost to follow-up: $(n=4)$

Reasons: 1 died

1 moved away

2 dropouts 1-year follow-up: $n=18$

2-year follow-up: $n=18$

Lost to follow-up $(n=5)$

Reasons: 2 died

2 moved away

1 dropout
Analysed after:

1-year follow-up: $n=23$

2-year follow-up: $n=19$
Analysed after:

1-year follow-up: $n=23$

2-year follow-up: $n=18$
Analysed after 1 year: $n=22$ No 2-year follow-up

Diagram 1. Selection Procedure and Distribution of the Sample. 
Analyses of the proportional distribution of the demographic and clinical characteristics of the three groups (68 participants) and of these 68 participants compared to the 30 dropouts can be seen in Table 1 .

As can be observed, the 68 participants of the three groups were homogeneous in all variables except for age. The participants of the PsT group were younger than those of the control groups, which did not differ in this variable. The age difference among groups was not associated with statistically significant differences in the dependent variables studied.

Comparisons of the 68 completers and the 30 dropouts did not show significant differences in any of the descriptors of the groups.

Table 1

Demographic and Clinical Background of Experimental Groups

\begin{tabular}{|c|c|c|c|c|c|c|c|c|c|c|c|c|}
\hline \multirow[b]{4}{*}{ Variable } & \multirow{2}{*}{\multicolumn{6}{|c|}{ Receptors of intervention }} & \multicolumn{6}{|c|}{ Total } \\
\hline & & & & & & & \multirow{3}{*}{$\begin{array}{l}\text { Analysis } \\
\chi^{2}(d f)\end{array}$} & \multicolumn{2}{|c|}{$\begin{array}{l}\text { Completers } \\
\quad(n=68)\end{array}$} & \multicolumn{2}{|c|}{$\begin{array}{l}\text { Noncompleters } \\
\quad(n=30)\end{array}$} & \multirow[b]{2}{*}{ Analysis } \\
\hline & \multicolumn{2}{|c|}{$\begin{array}{l}\text { Psychological } \\
\quad(n=23)\end{array}$} & \multicolumn{2}{|c|}{$\begin{array}{l}\text { Health Education } \\
\qquad(n=23)\end{array}$} & \multicolumn{2}{|c|}{$\begin{array}{l}\text { Control } \\
(n=22)\end{array}$} & & & & & & \\
\hline & $n$ & $\%$ & $n$ & $\%$ & $n$ & $\%$ & & $n$ & $\%$ & $n$ & $\%$ & $\chi^{2}(d f)$ \\
\hline Occupational status & & & & & & & $11.20(6)$ & & & & & $5.26(3)$ \\
\hline Executives & 3 & 13 & 7 & 30 & 1 & 4 & & 11 & 16 & 10 & 33 & \\
\hline Self-employed & 8 & 35 & 6 & 26 & 3 & 14 & & 17 & 25 & 8 & 27 & \\
\hline Clerical & 4 & 17 & 2 & 9 & 3 & 14 & & 9 & 13 & 1 & 3 & \\
\hline Manual Workers & 8 & 35 & 8 & 35 & 15 & 68 & & 31 & 46 & 11 & 37 & \\
\hline Employment status & & & & & & & $6.47(4)$ & & & & & $1.40(2)$ \\
\hline Retired & 4 & 17 & 5 & 22 & 7 & 32 & & 16 & 24 & 9 & 30 & \\
\hline Sick Leave/Unemploye & ed 11 & 48 & 16 & 69 & 9 & 41 & & 36 & 52 & 12 & 40 & \\
\hline Employed & 8 & 35 & 2 & 9 & 6 & 27 & & 16 & 24 & 9 & 30 & \\
\hline Educational level & & & & & & & $8.92(4)$ & & & & & $0.01(2)$ \\
\hline No studies & 3 & 13 & 9 & 39 & 11 & 50 & & 23 & 34 & 10 & 34 & \\
\hline Eighth grade & 12 & 52 & 8 & 35 & 9 & 41 & & 29 & 42 & 13 & 43 & \\
\hline High school /Graduate & 8 & 35 & 6 & 26 & 2 & 9 & & 16 & 24 & 7 & 23 & \\
\hline Marital status & & & & & & & $0.28(2)$ & & & & & $0.19(1)$ \\
\hline Married & 20 & 87 & 21 & 91 & 20 & 91 & & 61 & 90 & 26 & 87 & \\
\hline Other & 3 & 13 & 2 & 9 & 2 & 9 & & 7 & 10 & 4 & 13 & \\
\hline Smoking status & & & & & & & $1.62(4)$ & & & & & $0.06(2)$ \\
\hline Current smoker & 12 & 52 & 13 & 56 & 9 & 41 & & 34 & 50 & 16 & 53 & \\
\hline Previous smoker & 10 & 44 & 8 & 35 & 11 & 50 & & 29 & 43 & 12 & 40 & \\
\hline Never smoker & 1 & 4 & 2 & 9 & 2 & 9 & & 5 & 7 & 2 & 7 & \\
\hline \multicolumn{13}{|l|}{ Arteries with Significant } \\
\hline Stenosis $^{a}$ & & & & & & & $3.40(4)$ & & & & & $0.51(2)$ \\
\hline 1 & 6 & 35 & 4 & 24 & 6 & 37.5 & & 16 & 32 & 5 & 24 & \\
\hline 2 & 8 & 47 & 6 & 35 & 4 & 25.0 & & 18 & 36 & 9 & 43 & \\
\hline \multirow[t]{2}{*}{3} & 3 & 18 & 7 & 41 & 6 & 37.5 & & 16 & 32 & 7 & 33 & \\
\hline & $M$ & $S D$ & $M$ & $S D$ & $M$ & $S D$ & $F(2, .65)$ & $M$ & $S D$ & $M$ & $S D$ & $t(96)$ \\
\hline Age & 49.65 & 8.22 & 6.70 & 7.19 & 58.09 & 5.45 & $9.31 * * *$ & 54.76 & 7.90 & 52.90 & 6.27 & 1.14 \\
\hline FTAS & 0.55 & 0.26 & 0.51 & 0.25 & 0.47 & 0.23 & 0.59 & 0.51 & 0.24 & 0.45 & 0.29 & 1.03 \\
\hline SI & 90.00 & 9.01 & 90.42 & 9.21 & 90.04 & 7.12 & 0.02 & 90.15 & 8.36 & 90.43 & 15.98 & -0.16 \\
\hline MAI & 86.04 & 17.29 & 85.70 & 17.92 & 78.36 & 20.43 & 1.22 & 83.44 & 18.63 & 81.50 & 15.83 & 0.50 \\
\hline BDI & 11.87 & 6.86 & 14.52 & 6.43 & 16.18 & 5.44 & 2.71 & 14.16 & 6.44 & 13.90 & 7.40 & 0.17 \\
\hline
\end{tabular}

Note. FTAS: Framingham Type A Scale; SI: Structured Interview; MAI: Multidimensional Anger Inventory; BDI: Beck Depression Inventory.

${ }^{a}$ Data not available for all of the patients in the study.

$* * * p<.001$. 


\section{Type-A Behavior (FTAS)}

The posttreatment analyses showed a significant interaction Group $\chi$ Time of Measure, $F(2,65)=5.76, p<.01$, in the Total Scale. This interaction is represented in Figure 1.

The analyses indicated that there were no significant differences among groups before or after treatment. The within-group contrasts, however, showed significant differences between the first and second time of measurement in the PsT group, as can be seen in Table 2. This significant pre-post treatment reduction in the FTAS is due to changes in Factor 1 of the FTAS, Pressured Drive.

The analyses at 2-year follow-up showed a significant effect in the variation source time of measure, $F(3,105)=$ $4.97, p<.01$. This effect appeared only in the PsT group, as can be seen in Table 3 . The analyses by factors only showed

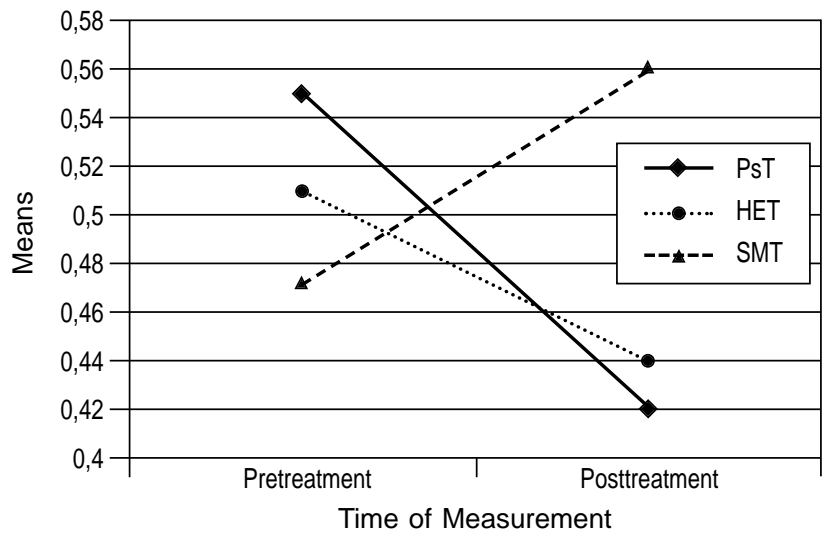

Figure 1. Interaction Group $\times$ Time of measurement in the Total Framingham Type-A Scale. PsT= Psychological Treatment; HET= Health Education Treatment; SMT $=$ Standard Medical Treatment.

Table 2

Pre-and Posttreatment Means, Standard Deviations, and Within-Group Contrasts in Type-A Behavior Patterns

\begin{tabular}{|c|c|c|c|c|c|c|c|c|}
\hline \multirow[b]{2}{*}{ Measure } & \multirow[b]{2}{*}{ Group } & \multirow[b]{2}{*}{$n$} & \multicolumn{2}{|c|}{ Pretreatment } & \multicolumn{2}{|c|}{ Posttreatment } & \multicolumn{2}{|c|}{ Within-group contrasts } \\
\hline & & & $M$ & $S D$ & $M$ & $S D$ & $F$ & $\delta$ \\
\hline \multicolumn{9}{|c|}{ Framingham Type-A Scale } \\
\hline \multicolumn{9}{|c|}{ Factor 1 Pressured Drive } \\
\hline & PsT & 23 & 63 & .26 & .40 & .33 & $12.47 * *$ & .74 \\
\hline & HET & 23 & .61 & .29 & .48 & .38 & 1.98 & .30 \\
\hline & SMT & 22 & .53 & .34 & .54 & .34 & 0.01 & -.02 \\
\hline \multicolumn{9}{|c|}{ Factor 2 Competitiveness/Impatience } \\
\hline & PsT & 23 & .49 & .32 & .43 & .32 & 1.49 & .27 \\
\hline & HET & 23 & .44 & .29 & .41 & .28 & 0.49 & .15 \\
\hline & SMT & 22 & .42 & .24 & .58 & .29 & $4.78^{*}$ & -.47 \\
\hline \multicolumn{9}{|c|}{ Total Scale } \\
\hline & PsT & 23 & .55 & .26 & .42 & .26 & $11.42 * *$ & .71 \\
\hline & HET & 23 & .51 & .25 & .44 & .22 & 2.47 & .33 \\
\hline & SMT & 22 & .47 & .23 & .56 & .21 & 2.55 & -.35 \\
\hline \multicolumn{9}{|c|}{ Structured Interview } \\
\hline \multicolumn{9}{|c|}{ Factor 1 Competitiveness/Hard driving } \\
\hline & PsT & 22 & 36.14 & 3.99 & 34.36 & 5.11 & 2.72 & .35 \\
\hline & HET & 21 & 36.52 & 4.12 & 36.29 & 4.21 & 0.10 & .07 \\
\hline & SMT & 22 & 36.00 & 4.14 & 36.14 & 3.69 & 0.03 & -.04 \\
\hline \multicolumn{9}{|c|}{ Factor 2 Anger-Out } \\
\hline & PsT & 22 & 28.95 & 4.18 & 27.50 & 5.14 & 2.52 & .34 \\
\hline & HET & 21 & 29.62 & 4.50 & 29.10 & 5.16 & 0.22 & .10 \\
\hline & SMT & 22 & 29.77 & 4.34 & 28.09 & 3.35 & 3.31 & .39 \\
\hline \multicolumn{9}{|c|}{ Factor 3 Speed/Impatience } \\
\hline & PsT & 22 & 24.91 & 4.13 & 22.32 & 3.56 & $10.79 * *$ & .70 \\
\hline & HET & 21 & 24.28 & 3.12 & 22.86 & 4.71 & 3.01 & .38 \\
\hline & SMT & 22 & 24.27 & 2.31 & 23.95 & 2.95 & 0.23 & .10 \\
\hline \multicolumn{9}{|c|}{ Total Structured Interview } \\
\hline & PsT & 22 & 90.00 & 9.01 & 84.18 & 11.45 & $8.24 * *$ & .62 \\
\hline & HET & 21 & 90.42 & 9.21 & 88.24 & 10.44 & 1.56 & .27 \\
\hline & SMT & 22 & 90.04 & 7.12 & 88.18 & 7.81 & 2.17 & .31 \\
\hline
\end{tabular}

Note. PsT: Psychological Treatment; HET: Health Education Treatment; SMT: Standard Medical Treatment. $\delta$ : Cohen's $\delta$.

$* p<.05 . * * p<.01$. 
a significant effect in Factor 1, Pressured Drive, $F(3,105)=$ $5.73, p=.001$. The post-hoc contrasts indicated that the significant differences in this factor corresponded exclusively to the changes of the PsT group. In this group and factor, there were reductions (at $p<.01$ ) between Times 1-2, 1-3 and 1-4.

\section{Type-A Behavior (Structured Interview)}

The posttreatment analyses showed a significant effect in the Total Scale only for the variation source time of measure, $F(1,62)=11.10, p=.001$. This effect was pinpointed in Factor 2, Anger-Out, $F(1,62)=4.67, p<.05$, and Factor 3, Speed/Impatience, $F(1,62)=10.83, p<.01$. The contrasts by groups indicated that in the Total Scale, significant reduction between the pre- and posttreatment times of measurement appeared only in the PsT group, as can be seen in Table 2. This significant reduction is due mainly to Factor 3, Speed/Impatience, in which only the PsT group showed significant differences between times of measurement. The significant effect in Factor 2, Anger-Out, vanished when analyzed by groups.
The analyses of the Total Scale results at 2-year followup showed that only the time of measure determined significant effects, $F(3,105)=2.92, p<.05$. The group contrasts indicated that the TABP diminished with a confidence level of .05 between the Time 1, before treatment, and all the other times of measurement only in the PsT group, as can be seen in Table 3. The analyses by factors indicated that only Factor 3, Speed-Impatience, and only in the PsT group, diminished significantly after training and that this change was maintained in the first and second year of follow-up.

\section{Anger( MAI)}

In the MAI Total Scale, a significant effect appeared in the variation source time of measure after the treatment, $F(1,65)=4.77, p<.05$, specifically, a significant reduction in the PsT group, as shown in Table 4. The effect is due to changes in Factor 1, Anger/Arousal, $F(1,65)=4.99, p<$ .05. Only the group that received PsT reduced its degree of physiological activation after the treatment.

Table 3

Pre- and Posttreatment Means, Standard Deviations, and Within-Group Contrasts in Anger and Depression

\begin{tabular}{|c|c|c|c|c|c|c|c|c|}
\hline \multirow[b]{2}{*}{ Measure } & \multirow[b]{2}{*}{ Group } & \multirow[b]{2}{*}{$n$} & \multicolumn{2}{|c|}{ Pretreatment } & \multicolumn{2}{|c|}{ Posttreatment } & \multicolumn{2}{|c|}{ Within-group contrasts } \\
\hline & & & $M$ & $S D$ & $M$ & $S D$ & $F$ & $\delta$ \\
\hline \multicolumn{9}{|c|}{ Multidimensional Anger Inventory } \\
\hline \multicolumn{9}{|c|}{ Factor 1: Anger/Arousal } \\
\hline & PsT & 23 & 33.48 & 10.29 & 29.26 & 9.61 & $9.36 * *$ & .64 \\
\hline & HET & 23 & 31.87 & 9.79 & 30.78 & 10.36 & 0.55 & .15 \\
\hline & SMT & 22 & 29.68 & 10.41 & 28.09 & 10.10 & 0.45 & .14 \\
\hline \multicolumn{9}{|c|}{ Factor 2: Hostile Outlook } \\
\hline & PsT & 23 & 16.30 & 4.37 & 15.65 & 4.47 & 0.67 & .17 \\
\hline & HET & 23 & 18.00 & 4.27 & 17.00 & 5.09 & 1.02 & .21 \\
\hline & SMT & 22 & 15.68 & 5.68 & 15.50 & 4.28 & 0.01 & .02 \\
\hline \multicolumn{9}{|c|}{ Factor 3: Anger-In } \\
\hline & PsT & 23 & 22.52 & 4.52 & 21.35 & 4.15 & 1.38 & .24 \\
\hline & HET & 23 & 22.17 & 3.78 & 20.87 & 4.93 & 2.01 & .29 \\
\hline & SMT & 22 & 19.95 & 4.13 & 20.54 & 5.78 & 0.18 & -.09 \\
\hline \multicolumn{9}{|c|}{ Factor 4: Anger-Out } \\
\hline & PsT & 23 & 13.74 & 3.56 & 13.39 & 3.47 & 0.22 & .10 \\
\hline & HET & 23 & 13.65 & 3.35 & 12.70 & 3.17 & 1.28 & .23 \\
\hline & SMT & 22 & 13.04 & 4.70 & 12.41 & 3.32 & 0.78 & .19 \\
\hline \multicolumn{9}{|c|}{ Total Inventory } \\
\hline & PsT & 23 & 86.04 & 17.29 & 79.65 & 18.57 & $5.85^{*}$ & .50 \\
\hline & HET & 23 & 85.70 & 17.92 & 81.35 & 19.38 & 2.59 & .34 \\
\hline & SMT & 22 & 78.36 & 20.43 & 76.54 & 19.20 & 0.17 & .09 \\
\hline \multicolumn{9}{|c|}{ Beck Depression Inventory } \\
\hline & PsT & 23 & 11.87 & 6.86 & 9.70 & 4.76 & 3.82 & .41 \\
\hline & HET & 23 & 14.52 & 6.43 & 14.35 & 6.13 & 0.28 & .03 \\
\hline & SMT & 22 & 16.18 & 5.44 & 13.32 & 4.32 & $5.65^{*}$ & .51 \\
\hline
\end{tabular}

Note. PsT: Psychological Treatment; HET: Health Education Treatment; SMT: Standard Medical Treatment. $\delta:$ Cohen's $\delta$.

$* p<.05 . * * p<.01$. 
Table 4

Means, Standard Deviations, and Within-Group Contrasts in Type-A Behavior Patterns at the Four Times of Measurement

\begin{tabular}{|c|c|c|c|c|c|c|c|c|c|c|c|c|c|c|c|c|}
\hline \multirow{3}{*}{ Measure } & \multirow{3}{*}{ Group } & \multirow{3}{*}{$n$} & \multicolumn{2}{|c|}{ Time 1} & \multicolumn{2}{|c|}{ Time 2} & \multicolumn{2}{|c|}{ Time 3} & \multicolumn{2}{|c|}{ Time 4} & \multicolumn{6}{|c|}{ Contrasts } \\
\hline & & & \multirow[t]{2}{*}{$M$} & \multirow[t]{2}{*}{$S D$} & \multirow[t]{2}{*}{$M$} & \multirow[t]{2}{*}{$S D$} & \multirow[t]{2}{*}{$M$} & \multirow[t]{2}{*}{$S D$} & \multirow[t]{2}{*}{$M$} & \multirow[t]{2}{*}{$S D$} & \multicolumn{2}{|c|}{$1-2$} & \multicolumn{2}{|c|}{$1-3$} & \multicolumn{2}{|c|}{$1-4$} \\
\hline & & & & & & & & & & & $F$ & $\delta$ & $F$ & $\delta$ & $F$ & $\delta$ \\
\hline \multicolumn{17}{|c|}{ Framingham Type-A Scale } \\
\hline \multicolumn{17}{|c|}{ Factor 1: Pressured Drive } \\
\hline & PsT & 19 & 0.60 & 0.24 & 0.38 & 0.35 & 0.30 & 0.31 & 0.32 & 0.25 & $8.61 * *$ & .67 & $17.19 * * *$ & $* .93$ & $15.02 * * *$ & $* .79$ \\
\hline & HET & 18 & 0.61 & 0.32 & 0.50 & 0.35 & 0.49 & 0.34 & 0.50 & 0.34 & 1.36 & .28 & 1.72 & .32 & 1.30 & .27 \\
\hline \multicolumn{17}{|c|}{ Factor 2: Competitiveness/Impatience } \\
\hline & PsT & 19 & 0.49 & 0.34 & 0.43 & 0.33 & 0.42 & 0.33 & 0.45 & 0.32 & 1.15 & .24 & 1.20 & .25 & 0.35 & .12 \\
\hline & HET & 18 & 0.48 & 0.31 & 0.44 & 0.30 & 0.44 & 0.32 & 0.43 & 0.31 & 0.49 & .17 & 0.30 & .14 & 0.52 & .18 \\
\hline \multicolumn{17}{|c|}{ Total Scale } \\
\hline & PsT & 19 & 0.54 & 0.26 & 0.41 & 0.28 & 0.37 & 0.24 & 0.39 & 0.22 & $8.06^{* *}$ & .68 & $12.57 * *$ & .85 & $5.92 *$ & 60 \\
\hline & HET & 18 & 0.53 & 0.28 & 0.47 & 0.25 & 0.46 & 0.25 & 0.46 & 0.20 & 1.89 & .24 & 1.48 & .28 & 1.53 & .27 \\
\hline \multicolumn{17}{|c|}{ Structured Interview } \\
\hline \multicolumn{17}{|c|}{ Factor 1: Competitiveness/Hard driving } \\
\hline & PsT & 19 & 36.21 & 4.28 & 34.95 & 5.16 & 34.63 & 4.92 & 34.32 & 4.08 & 1.26 & .26 & 2.35 & .35 & 2.22 & .34 \\
\hline & HET & 18 & 36.22 & 3.96 & 36.22 & 4.49 & 37.61 & 4.67 & 37.33 & 4.10 & 0.00 & .00 & 2.44 & -.37 & 1.84 & -.32 \\
\hline \multicolumn{17}{|c|}{ Factor 2: Anger-Out } \\
\hline & PsT & 19 & 29.37 & 4.23 & 27.68 & 5.36 & 27.21 & 4.40 & 27.58 & 5.26 & 3.39 & .42 & 3.66 & .44 & 2.46 & .36 \\
\hline & HET & 18 & 29.00 & 4.37 & 29.33 & 4.58 & 27.78 & 3.74 & 27.83 & 4.55 & 0.09 & -.07 & 1.06 & .24 & 1.11 & .25 \\
\hline \multicolumn{17}{|c|}{ Factor 3: Speed/Impatience } \\
\hline & PsT & 19 & 24.79 & 4.37 & 22.42 & 3.63 & 22.95 & 3.96 & 22.05 & 3.27 & $7.54 * *$ & .63 & $4.63 *$ & .49 & $9.49 * *$ & .71 \\
\hline & HET & 18 & 24.39 & 2.91 & 22.72 & 4.69 & 23.44 & 4.69 & 23.22 & 3.44 & 3.04 & .41 & 1.32 & .27 & 2.50 & .37 \\
\hline \multicolumn{17}{|c|}{ Total Structured Interview } \\
\hline & PsT & 19 & 90.37 & 9.53 & 85.05 & 11.78 & 84.79 & 10.61 & 83.95 & 10.48 & $6.27 *$ & .58 & $6.46^{*}$ & .58 & $7.31 * *$ & .52 \\
\hline & HET & 18 & 89.61 & 8.66 & 88.28 & 10.72 & 88.83 & 10.85 & 88.39 & 10.44 & 0.45 & .15 & 0.10 & .07 & 0.37 & .14 \\
\hline
\end{tabular}

Note. PsT: Psychological Treatment; HET: Health Education Treatment; SMT: Standard Medical Treatment. $\delta$ : Cohen's $\delta$.

$* p<.05 . * * p<.01 . * * * p<.001$.

In the MAI Total Scale at the 2-year follow-up, only the time of measure revealed a significant effect, $F(3,105)=$ $6.43, p<.001$. As can be seen in Table 5, when analyzing by times of measure and groups, this significant effect appeared between the Time 1 , before treatment, and all the other times of measurement only in the PsT group. In the HET group, this effect appeared between Times 1-3 and 14. The analyses by factors of the MAI showed significant reductions in Factor 1, Anger/Arousal, $F(3,105)=9.09, p<$ .001 , and Factor 3, Anger-In, $F(3,105)=6.84, p<.001$. The analyses of these significant effects by groups indicated that differences in Anger/Arousal appeared in the PsT group between Time 1 and all the other times of measurement, and in the HET group between Times 1-3 and 1-4. The differences in Anger-In were observed in PsT group between Times 1-3 and 1-4, and in the HET group between Times 1-3.

\section{Depression (BDI)}

The posttreatment results revealed significant effects in time of measure, $F(1,65)=7.27, p<.01$, and group,
$F(2,65)=4.27, p<.05$. The significant difference between times of measure consisted of a significant reduction of the BDI scores in the members of the SMT group, as can be seen in Table 4. There was a significant group difference between the members of the PsT and HET groups, $F(2$, $65)=5.18, p<.01, \delta=.79$, with the PsT participants scoring lower than the members of the HET group after treatment.

The results at 2-year follow-up yielded only a significant effect of group, $F(1,35)=8.58, p<.01$. The post hoc analysis indicates that the groups did not differ at the confidence level of .05 in depression before treatment, but in the three following times of measurement, the PsT group scored significantly lower in depression than the group that received HET, $t(35)=2.60, p<.05, \delta=$ $.79, t(35)=2.47, p<.05, \delta=.76$, and $t(35)=3.39, p<$ $.01, \delta=.98$, respectively, for the group comparisons between Times 2, 3, and 4. The progressive reduction of depression in the PsT group is revealed by a significant within-group difference between the Times 1-4, as can be seen in Table 5. 
Table 5

Means, Standard Deviations, and Within Group-Contrasts in Anger and Depression at the Four Times of Measurement

\begin{tabular}{|c|c|c|c|c|c|c|c|c|c|c|c|c|c|c|c|c|}
\hline \multirow{3}{*}{ Measure } & \multirow{3}{*}{ Group } & \multirow{3}{*}{$n$} & \multicolumn{2}{|c|}{ Time 1} & \multicolumn{2}{|c|}{ Time 2} & \multicolumn{2}{|c|}{ Time 3} & \multicolumn{2}{|c|}{ Time 4} & \multicolumn{6}{|c|}{ Contrasts } \\
\hline & & & \multirow[t]{2}{*}{$M$} & \multirow[t]{2}{*}{$S D$} & \multirow[t]{2}{*}{$M$} & \multirow[t]{2}{*}{$S D$} & \multirow[t]{2}{*}{$M$} & \multirow[t]{2}{*}{$S D$} & \multirow[t]{2}{*}{$M$} & \multirow[t]{2}{*}{$S D$} & \multicolumn{2}{|c|}{$1-2$} & \multicolumn{2}{|c|}{$1-3$} & \multicolumn{2}{|c|}{$1-4$} \\
\hline & & & & & & & & & & & $F$ & $\delta$ & $F$ & $\delta$ & $F$ & $\delta$ \\
\hline \multicolumn{17}{|c|}{ Multidimensional Anger Inventory } \\
\hline \multicolumn{17}{|c|}{ Factor 1: Anger/Arousal } \\
\hline & PsT & 19 & 34.53 & 9.84 & 28.79 & 9.72 & 27.16 & 9.72 & 27.68 & 9.73 & $13.18 * *$ & .83 & $15.65 * * *$ & .91 & $12.20 * *$ & .80 \\
\hline & HET & 18 & 33.06 & 9.94 & 31.50 & 10.12 & 28.11 & 8.25 & 26.33 & 9.96 & 0.72 & .20 & $4.77 *$ & .51 & $6.62 *$ & .61 \\
\hline \multicolumn{17}{|c|}{ Factor 2: Hostile Outlook } \\
\hline & PsT & 19 & 15.89 & 4.33 & 15.42 & 4.66 & 14.26 & 4.27 & 15.32 & 5.16 & 0.24 & .11 & 2.08 & .33 & 0.19 & .10 \\
\hline & HET & 18 & 18.28 & 3.71 & 17.33 & 5.31 & 17.16 & 4.77 & 16.22 & 4.44 & 0.67 & .19 & 0.93 & .23 & 2.80 & .39 \\
\hline \multicolumn{17}{|c|}{ Factor 3: Anger-In } \\
\hline & PsT & 19 & 22.21 & 4.43 & 21.37 & 4.43 & 18.79 & 4.18 & 19.10 & 3.72 & 0.53 & .17 & $7.60 *$ & .63 & $6.16^{*}$ & .57 \\
\hline & HET & 18 & 22.22 & 3.84 & 21.11 & 4.81 & 19.16 & 3.17 & 19.11 & 5.39 & 1.38 & .28 & $6.20 *$ & .59 & 3.90 & .46 \\
\hline \multicolumn{17}{|c|}{ Factor 4: Anger-Out } \\
\hline & PsT & 19 & 13.21 & 3.57 & 13.00 & 3.38 & 12.58 & 3.91 & 12.74 & 3.97 & 0.06 & .06 & 0.42 & .15 & 0.28 & .12 \\
\hline & HET & 18 & 13.67 & 3.65 & 12.89 & 3.32 & 13.11 & 3.80 & 13.94 & 4.40 & 0.65 & .19 & 0.38 & .14 & 0.06 & -.06 \\
\hline \multicolumn{17}{|c|}{ Total Inventory } \\
\hline & PsT & 19 & 85.84 & 15.95 & 78.58 & 19.12 & 72.79 & 17.40 & 74.84 & 17.95 & $5.84^{*}$ & .55 & $11.94 * *$ & .79 & $7.85^{*}$ & .64 \\
\hline & HET & 18 & 87.22 & 18.55 & 81.66 & 18.77 & 77.56 & 15.61 & 75.61 & 19.51 & 3.11 & .42 & $4.56^{*}$ & .50 & $5.55^{*}$ & .56 \\
\hline \multicolumn{17}{|c|}{ Beck Depression Inventory } \\
\hline & PsT & 19 & 10.68 & 6.45 & 9.37 & 4.64 & 9.63 & 4.00 & 7.95 & 2.92 & 1.56 & .29 & 0.84 & .21 & $4.26^{*}$ & .47 \\
\hline & HET & 18 & 13.39 & 5.44 & 14.00 & 6.13 & 13.44 & 5.34 & 12.17 & 4.53 & 0.29 & -.13 & 0.00 & .01 & 0.89 & .22 \\
\hline
\end{tabular}

Note. PsT: Psychological Treatment; HET: Health Education Treatment. $\delta$ : Cohen's $\delta$.

$* p<.05 . * * p<.01 . * * * p<.001$.

\section{Discussion}

The distinctive characteristic of this study is that it involved male coronary patients of low socio-economic level, a group traditionally under-represented in intervention programs (Smith et al., 2002). This study had few participation limitations, so that the results obtained could be extended to male CHD patients living in the Canary Islands and receiving attention through the public health services. This generalization, however, might be modulated by the percentage of patients who decided not to participate, $7.98 \%$, and by the high percentage of patients who, after agreeing while in hospital to participate in the program, either did not turn up for the first meeting $(49.31 \%)$, or who came to the first session but did not return to the second session to sign their free consent (5.94\%). We put this down to two main factors: lack of information about the positive effects of these programs on patients' health and quality of life and the medical staff's lack of involvement and interest in these programs. However, there could also be economic and social factors involved, as the patients with lower attendance at the group meetings were people with considerably lower incomes and educational level.

The dropout rate during the year of treatment hardly reaches $31 \%$, a lower percentage than the one provided in population-based studies (Chambless \& Ollendick, 2001) and practically identical to that reported in studies about the effectiveness of treatments with specially controlled groups (Elkin et al., 1989).

In our case, we consider the length of the treatment to be appropriate because we are dealing with a lifestyle that develops over many years, invades all the domains of a person's life, and is based on the most intimate aspects of personality (Friedman, 1996). Despite this relatively long treatment, the dropout rate is less than that of similar studies, a result that indicates that the treatment program fulfilled the participants' needs and expectations. Notwithstanding, the estimated percentage of participants who either did not take part in the program or who abandoned it cautions us about the importance of the presentation and development of the program in order to attain its aims. We believe that for coronary patients to enroll and participate thoroughly in these programs, as Johnston, Johnston, Pollard, Kinmonth, and Man (2004) suggest, we should convince them of the efficacy and positive results of psychological treatments.

The participants' health and socioeducational characteristics are very homogenous, in spite of the fact that assignation to the SMT group was not random. The only significant difference among the groups was the lower average age of those in the PsT group, which, in fact, would imply the 
likelihood of a greater presence of the TABP in this group previous to the treatment (Dielman, Butchart, \& Moss, 1990), and so lend greater emphasis to the results obtained.

The results after the year of treatment indicate, in the first place, that the PsT is effective in modifying some components of the TABP, as the application of the program resulted in a reduction of Pressured Drive (Factor 1 of the FTAS) and Speed-Impatience (Factor 3 of the SI) only in the PsT group, whereas in the HET and in the SMT groups, there was no reduction of these or other TABP components. The results at the 2-year follow-up reinforce the results obtained after the year of training. The significant reduction of Pressured Drive and Speed-Impatience were maintained in the following measurement times only in the PsT group, and this reduction is reflected in the significant changes in the total scales. These changes are congruent with the content of the sessions specifically designed for these groups to reduce behavioral tension by controlling time urgency and dominating haste.

The results of Anger, a central component of the TABP, are unclear. The significant posttreatment reduction in AngerOut (Factor 2 of the SI and Factor 3 of the MAI) disappeared when analyzed by groups, and only Anger/Arousal (Factor 1 of the MAI) was modified in the group that received PsT after treatment and at the 2-year follow-up. The Anger/Arousal result is coherent with the relaxation training over $1 \frac{1}{2}$ months and the brief relaxation practice at every session, but the reductions in Anger/Arousal and Anger-In in the HET group suggest that the group meetings themselves and the time factor are also contributing to these effects.

The results in depression indicate that after the treatment, only the group that received SMT showed a significant reduction in depression. We think this change can be considered a regression to the group mean, as before treatment, the score of the SMT group was higher (16.41) than that of the groups that received PsT (11.87) or HET, (14.52). After the year of treatment, the SMT group obtained a score in depression of 13.32, approximately the mean of the three groups before and after the treatment. After treatment, the PsT group did not present statistically significant within-group changes, but its initial scores dropped after treatment and continued to decrease during the 2-year follow-up, until finally showing a statistically significant change between Times 1-4. This progressive reduction of depression scores, similar to that obtained by Evon and Burns (2004), is reflected in significant differences between the PsT and HET groups in the Times 2, 3, and 4, although these groups did not differ in depression before treatment. The progressive reduction in depression scores exclusively in the PsT group could indicate that the content and development of their program helped them specifically with this problem.

We conclude that the treatment designed to modify coronary-prone behaviors was able to modify some behavioral components of the TABP-Pressured Drive and Speed-Impatience-but not the components with a more emotional content or those involving a deeper strata of the personality, such as anger and competitiveness. Physiological activation and, above all, depression were also modified by the psychological treatment. These results are coherent with the generally positive results obtained in other studies, in spite of our having used comparatively long intervention periods and working with people from a low socioeconomic background. We can therefore state that we now have an effective treatment package available, to be dismantled and adjusted to the specific needs of coronary patients.

\section{References}

Beck, A.T., Ward, C.H., Mendelson, M., Mock, J., \& Erbaugh, J. (1961). An inventory for measuring depression. Archives of General Psychiatry, 4, 561-71.

Conde, V., Esteban, T., \& Useros, E. (1976). Revisión crítica de la adaptación castellana del cuestionario de Beck. Revista de Psicología General y Aplicada, 31, 469-97.

Chambless, D.L., \& Ollendick, Th. (2001). Empirically supported psychological interventions: Controversies and evidence. Annual Review of Psychology, 52, 685-716.

Chesney, M.A. Eagleston, J.R., \& Rosenman, R.H. (1980). The Type A Structured Interview: A behavioral assessment in the rough. Journal of Behavioral Assesment, 2, 255-272.

Dielman, T.D., Butchart, A.T., \& Moss, G.E. (1990). Demographic differences in the relationships among components and global ratings of structured interview-assessed Type-A behavior in a population sample. In M.J. Strube (Dir.), Type A behavior (Special Issue), Journal of Social Behavior and Personality, 5, 233-61.

Dusseldorp, E., van Elderen, T., Maes, S., Meulman, J., \& Kraaij, V. (1999). A meta-analysis of psycho-educational programs for coronary heart disease patients. Health Psychology, 18, 50619.

Elkin, I., Shea, T., Walkins, J., Imber, S., Sotsky, S., Collins, J., Glass, D., Pilkonis, P., Leber, W., Docherty, J., Fiester, S., \& Parloff, M. (1989). National Institute of Mental Health Treatment of Depression Collaborative Research Program: General effectiveness of treatments. Archives of General Psychiatry, 46, 971-82.

Evon, D.M., \& Burns, J.W. (2004). Process and outcome in cardiac rehabilitation: An examination of cross-lagged effects. Journal of Consulting and Clinical Psychology, 72, 605-616.

Fernández-Abascal, E., Martín, M. D., \& Domínguez, F.J. (2003). Factores de riesgo e intervenciones psicológicas eficaces en los trastornos cardiovasculares. Psicothema, 15, 615-630.

Friedman, M. (1996). Type A behavior: Its diagnosis and treatment. New York: Plenum Press.

Haynes, S., Levine, S., Scotch, N., Feinleib, M., \& Kannel, W.B. (1978). The relationship of psychosocial factors to coronary heart disease in the Framingham study: I. Methods and risk factors. American Journal of Epidemiology, 107, 362-83. 
Houston, B.K., Smith, Th.W., \& Zuraswski, R.M. (1986). Principal dimensions of the Framingham Type A Scale: Differential relationships to cardiovascular reactivity and anxiety. Journal of Human Stress, Fall Issue, 105-12.

Johnston, D. W., Johnston, M., Pollard, B., Kinmonth, \& Man, D. (2004). Motivation is not enough: Prediction of risk behavior following diagnosis of coronary heart disease from the theory of planned behavior. Health Psychology, 23, 533-538.

Kazdin, A.E., \& Wilson, G.T. (1978). Evaluation of behavior therapy: Issues, evidence, and research strategies. Cambridge. MA: Ballinger.

Linden, W., Stossel, C., \& Maurice, J. (1996). Psychosocial interventions for patients with coronary artery disease. A metaanalysis. Archives of Internal Medicine, 156, 745-52.

Nunes, E.V., Frank, K.A., \& Kornfeld, D.S. (1987). Psychologic treatment for the type A behavior pattern and for coronary heart disease: A meta-analysis of the literature. Psychosomatic Medicine, 48, 159-73.

Pino, A. del (1998). Tratamiento cognitivo-conductual para modificar el patrón de conducta tipo A. In V.E. Caballo (Dir.), Manual para el tratamiento cognitivo-conductual de los trastornos psicológicos. (Vol. 2, pp. 359-383). Madrid: Siglo Veintiuno de España Editores.

Pino, A. del, Borges, A., Díaz, S., Suárez, D., \& Rodríguez, I. (1990). Propiedades psicométricas de la Escala Tipo A de Framingham. Psiquis, 11, 19-30.
Pino, A. del, Gaos, M.T., \& Dorta, R. (1997). Validación cruzada de la Escala Tipo A de Framingham y de la Escala Breve de Bortner en una muestra de varones canarios Psicología Conductual, 5, 377-90.

Pino, A. del, Gaos, M.T., \& Dorta, R. (1999). Construct and criterion-oriented validity of the structured interview for the assessment of the type-A behaviour pattern in a sample of Canarian males. European Journal of Psychological Assessment, $15,39-48$.

Roskies, E. (1987). Stress management for healthy Type A's. New York: Guilford.

Sánchez-Elvira, A., Pérez, A., \& Bermúdez, J. (May, 1991). Variables psicosociales asociadas a la presencia de índices de riesgo cardiovascular: el Proyecto Salud. II Semana de Investigación de la Facultad de Psicología. Madrid, UNED (National Spanish Open University).

Siegel, J.M. (1986). The Multidimensional Anger Inventory. Journal of Personality and Social Psychology, 51, 191-200.

Smith, Th.W., Kendall, Ph.C., \& Keefe, F.J. (2002). Behavioral medicine and clinical health psychology: Introduction to the special issue. A view from the decade of behavior. Journal of Consulting and Clinical Psychology, 70, 459-62.

Received: November. 21, 2004 Review received: January 26. 2005 Accepted: February 4, 2005 